\title{
Clôture du congrès
}

Jean-Guy Hamelin

Volume 49, 1982

URI : https://id.erudit.org/iderudit/1007095ar

DOI : https://doi.org/10.7202/1007095ar

Aller au sommaire du numéro

Éditeur(s)

Les Éditions Historia Ecclesiæ Catholicæ Canadensis Inc.

ISSN

0318-6172 (imprimé)

1927-7067 (numérique)

Découvrir la revue

Citer ce document

Hamelin, J.-G. (1982). Clôture du congrès. Sessions d'étude - Société canadienne d'histoire de l'Église catholique, 49, 85-86. https://doi.org/10.7202/1007095ar

Tous droits réservés @ Les Éditions Historia Ecclesiæ Catholicæ Canadensis Inc., 1982
Ce document est protégé par la loi sur le droit d'auteur. L'utilisation des services d'Érudit (y compris la reproduction) est assujettie à sa politique d'utilisation que vous pouvez consulter en ligne.

https://apropos.erudit.org/fr/usagers/politique-dutilisation/ 


\section{Clôture du congrès}

\section{Chers congressistes,}

Mon premier mot est d'abord pour vous remercier d'avoir choisi Rouyn-Noranda comme lieu de votre rencontre de 1982. La qualité de l'accueil de chez nous est reconnue à bien des kilomètres à la ronde. Vous comprenez cependant que nous sommes d'autant plus sensibles à votre geste que vous veniez partager avec nous quelques parcelles de vos richesses et stimuler notre fierté et notre attachement à un coin de pays que nous aimons beaucoup.

Parce qu'en fait, l'histoire, même si elle a comme objectif de connaître et faire connaître les actions de ceux qui nous ont précédés, provoque pour nous qui les suivons un juste sentiment d'admiration et un souci de continuer l'oeuvre commencée. Au coeur de tout héritage, il y a un défi de projet. L'histoire qui n'est pas seulement un étalage de dates et de statistiques mais une pénétration au coeur des événements et des hommes remue toujours ceux qui ne veulent pas être indifférents au destin de leurs compatriotes.

Lorsqu'il s'agit de l'histoire d'une institution porteuse de valeurs de vie et ferment de société comme l'est l'Église catholique, on perçoit l'importance du rôle joué par les historiens de cette Église. La mission confiée par Jésus à ses apôtres a été assumée par des hommes et des femmes en chair et en os; elle s'est incarnée dans des structures qui ont servi de véhicule au message évangélique; elle a eu une influence sur bien d'autres institutions et sur la grande société en général. Relever tout cela, et le transmettre à des concitoyens et concitoyennes, avec toutes les faiblesses d'ailleurs que cela nous fait découvrir, est source de fécondes réflexions et de dynamisme pour l'action.

Quand on est pasteur d'une jeune communauté - effectivement, Rouyn-Noranda est le dernier-né des diocèse du Canada - on ne peut s'empêcher de contempler le chemin parcouru par d'autres Églises au panache plus développé. Mais il ne faut pas oublier qu'avant de 
devenir Église de Rouyn-Noranda, notre terre avait produit ses apôtres et inscrit à son palmarès une brochette de hauts faits apostoliques. Jeune évêque, je me suis délecté des récits de vieux colonisateurs qui avaient planté l'Église ici. Vos délibérations nous en ont dévoilé des aspects aux facettes inédites.

Je veux remercier tous les artisans de ce congrès, tous ceux qui en ont assuré la réussite par leur travail de préparation et par leur participation. Les travaux présentés étaient de quaiité : ieurs auteurs méritent nos félicitations et notre gratitude. On me permettra un merci bien spécial et affectueusement fraternel au Père Martineau qui est, chez nous, un symbole vivant de l'amour de l'histoire et de l'attachement à l'héritage.

Mesdames, messieurs, je vous dis la reconnaissance du diocèse de Rouyn-Noranda. Votre passage ici sera certainement pour nous richesse et stimulant. Puissiez-vous retourner dans vos régions avec quelques bribes de notre histoire qui gonfleront votre bagage de connaissance et qui sait, aideront peut-être à faire grandir notre Église du Québec et du Canada.

Jean-Guy HaMELIN, Évêque de Rouyn-Noranda. 